\title{
Importância da análise da proteína Pax-5 no diagnóstico diferencial entre linfoma de Hodgkin e linfoma difuso de grandes células B em biópsias de mediastino
}

\author{
The importance of Pax-5 protein immunostaining in the differential diagnosis between Hodgkin's \\ lymphoma and diffuse large B-cell lymphoma in biopsies of the mediastinum
}

\author{
Michelle M. Barcelos ${ }^{1}$ \\ Andréia L. F. Navarini ${ }^{2}$ \\ Robson W. Bellettini ${ }^{2}$ \\ Lee I-Ching ${ }^{3}$ \\ Maria Cláudia Santos- Silva ${ }^{4}$
}

\begin{abstract}
O linfoma de Hodgkin (LH) e o linfoma difuso de grandes células $B$ (LDGCB) são neoplasias derivadas de células $B$, que apresentam marcadores imunofenotipicos em comum, e, por isso, em alguns casos onde ocorre sobreposição morfológica torna-se difícil o diagnóstico diferencial entre eles. $O$ grau de dificuldade aumenta quando o tumor é localizado no mediastino. O fato de a biópsia de mediastino ser um procedimento ainda mais invasivo que a maioria das outras biópsias, muitas vezes faz com que sejam coletadas quantidades insuficientes de amostra, o que dificulta a análise das características morfológicas da linfoproliferação. Considerando tais dificuldades, neste trabalho investigaremos a expressão imuno-histoquímica da proteína Pax-5 no diagnóstico diferencial de LH e LDGCB. Foram analisadas amostras de 14 pacientes, sendo dez com LDGCB e quatro com LH. O estudo imunohistoquímico com Pax-5 mostrou 100\% de positividade nuclear para LDGCB. Porém, destes, $30 \%$ mostraram positividade forte $(+++) ; 50 \%$ moderada $(++) ; 20 \%$ fraca (+). Já nas amostras de LH, 50\% obtiveram marcação focal e fraca nas células de Reed/Sternberg (CRS) e 50\% foram negativas. A marcação focal e fraca, ou até negativa, do Pax-5 em LH pode ser um ponto importante para o diagnóstico diferencial, uma vez que difere muito da marcação visualizada no LDGCB. Assim, é possivel concluir que o anticorpo Pax-5 é um bom marcador para ser usado em conjunto com outros marcadores no painel de rotina e, quando associado à clínica, pode ser muito útil no diagnóstico diferencial entre $L D G C B$ e LH em linfoma de mediastino. Rev. Bras. Hematol. Hemoter.
\end{abstract}

Palavras-chave: Linfoma de Hodgkin; linfoma difuso de grandes células B; PAX-5; imuno-histoquÍmica

\footnotetext{
${ }^{\text {I} B i o q u i ́ m i c a ~ n o ~ L a b o r a t o ́ r i o ~ d e ~ H e m o p a t o l o g i a ~ d o ~ C e n t r o ~ d e ~ P e s q u i s a s ~ O n c o l o ́ g i c a s ~(C e p o n) . ~}$

${ }^{2}$ Farmacêutica(o)-Bioquímica(o).

${ }^{3}$ Médica Patologista no Departamento de Anatomia-Patológica da Universidade Federal de Santa Catarina (UFSC) e do

Centro de Pesquisas Oncológicas (Cepon).

${ }^{4}$ Professora Adjunta do Departamento de Análises Clinicas da Universidade Federal de Santa Catarina (UFSC).
}

Universidade Federal de Santa Catarina - Florianópolis-SC

Correspondência: Maria Cláudia Santos-Silva

Departamento de Análises Clínicas, Centro de Ciências da Saúde

Universidade Federal de Santa Catarina - UFSC - Campus Universitário - Trindade

88040-970 - Florianópolis-SC - Brasil

Tel.: (55 48) 3721-8146 - Fax: (55 48) 3721-9542

E-mail: maclau@ccs.ufsc.br

Doi: 


\section{Introdução}

Os linfomas compreendem um grupo heterogêneo de doenças causadas por linfócitos malignos, que usualmente se acumulam nos linfonodos e ocasionalmente podem atingir o sangue periférico (fase leucêmica) ou infiltrar outros órgãos fora do tecido linfoide. Os linfomas são divididos em linfoma de Hodgkin (LH) e linfoma não Hodgkin (LNH), com base na presença histológica de células de Reed-Sternberg (CRS) no LH. ${ }^{1}$

O LH, descrito por Thomas Hodgkin em 1832, pode ser definido como uma neoplasia hematológica de origem linfoide, caracterizada histopatologicamente pela proliferação de células neoplásicas de morfologia variável, denominadas células de Reed-Sternberg (CRS), as quais estão imersas em substrato celular de aspecto inflamatório característico. A origem da célula de RS é controversa, pois praticamente todas as células do sistema imune já foram consideradas células precursoras das células de RS. Recentemente, definiu-se como sendo de origem linfoide. Porém, um grande debate se abriu em relação à linhagem, se as mesmas são de células $\mathrm{T}$ ou de células B. ${ }^{2}$ Estudos moleculares mostraram que, na maioria dos casos, as células malignas são derivadas de células B do centro germinal, enquanto, em poucos casos, as células de RS mostraram originar-se a partir de células T. ${ }^{3}$

A Organização Mundial de Saúde (OMS), em conjunto com a Sociedade Americana de Hematologia e a Associação Européia de Hematologia, revisaram, em 2008, a classificação para neoplasias dos tecidos hematopoético e linfoide (Revised European-American Lymphoma/World Health Organization: REAL/WHO), publicada em 2001. Nessa classificação, o LH foi dividido em dois tipos histológicos: linfoma de Hodgkin predominância linfocítica nodular (LHPLN) e linfoma de Hodgkin clássico (LHC). Dentro do LHC, quatro subtipos foram diferenciados: esclerose nodular - tipo I e tipo II (LHCEN), rico em linfócitos (LHCRL), celularidade mista (LHCCM) e depleção linfocítica (LHCDL). Para a classificação dos linfomas não Hodgkin (LNH), o sistema REAL/WHO considerou a morfologia das células linfoides, a presença de proteínas na superfície das células (imunofenotipagem) e as características genéticas. Além disso, os vários tipos de LNH foram agrupados conforme o tipo de célula linfoide do tipo B ou T, e, de acordo com o prognóstico, em: indolentes, agressivos e muito agressivos. ${ }^{4,5,6}$ A imuno-histoquímica tem valor diagnóstico diferencial entre os subtipos tradicionais de LH, assim como na distinção de outras desordens linfoproliferativas com CRS símile. ${ }^{7} \mathrm{O}$ LH pode ser confundido com alguns LNH, principalmente com o linfoma difuso de grandes células B (LDGCB) ${ }^{8,9}$ com linfoma de células B, rico em células T ou histiócitos ${ }^{10,11}$ e com linfomas de células T periféricas. ${ }^{12}$

Histopatologicamente, os LNH caracterizam-se por células aparentemente linfocíticas com variados graus de diferenciação, dependendo do tipo de linfoma. No LDGCB, observam-se grandes células blásticas, com cromatina frouxa, nucléolos proeminentes, citoplasma basofílico, semelhantes a centroblastos e imunoblastos. ${ }^{2}$ Quando primário de mediastino, o LDGCB possui células B clonais de origem tímica, e epidemiologicamente ocorre predominantemente em mulheres jovens. ${ }^{4}$

O LH e o LDGCB são neoplasias de células B que apresentam marcadores imunofenotípicos em comum, e, por isso, em alguns casos onde ocorre sobreposição morfológica, torna-se difícil o diagnóstico diferencial entre eles, ${ }^{13}$ principalmente em biópsias de mediastino. Como a biópsia de mediastino é um procedimento muito invasivo, geralmente a quantidade de amostra coletada do paciente é insuficiente e inadequada para a análise anatomopatológica e imunohistoquímica da linfoproliferação. Desta forma, a investigação de um marcador específico para esses linfomas torna-se um alvo de diagnóstico laboratorial de grande importância. Usualmente, o diagnóstico diferencial entre essas duas neoplasias faz-se pela análise da marcação específica dos anticorpos CD30, CD15, e FASCINA para linfoma de Hodgkin e a negatividade do LCA. Já para o linfoma difuso de grandes células $\mathrm{B}$, a literatura mostra marcação positiva para o anticorpo LCA e negativa para CD15. Outros anticorpos também podem ser utilizados na análise complementar desses linfomas, como o CD20, CD3, CD40, CD45 RO, CD5, EBV e ALK1. ${ }^{4,14}$

Recentemente, o fator de transcrição Pax-5 foi demonstrado como um importante marcador de diferenciação de células B. ${ }^{15} \mathrm{O}$ Pax-5 pertence à família dos genes Paired Box (Pax), a qual é composta, em humanos, por nove genes conservados. ${ }^{16}$ Pelo menos quatro diferentes isoformas dessa proteína foram identificadas e, das quais, a isoforma Pax-5a tem sido a mais estudada. ${ }^{17-20}$ Os genes Pax são reguladores importantes do desenvolvimento embrionário e organogênese. No entanto, muitos membros da família Pax, como o Pax-5, também exercem funções cruciais no indivíduo adulto. Além disso, os genes Pax também podem atuar como próoncogenes e ter o potencial de induzir transformações neoplásicas. ${ }^{16,20,21,22}$ Os genes paired Box codificam uma família de proteínas regulatórias envolvidas no controle transcricional de desenvolvimento de tecidos e diferenciação celular. O gene Pax-5 humano está localizado no cromossomo 9q13 e foi inicialmente encontrado codificando proteínas nucleares ligantes de DNA em células B, conhecida como proteína ativadora específica de células $\mathrm{B}$ (PASB). ${ }^{23}$ A proteína Pax-5, ou PASB, exerce um papel muito importante no desenvolvimento, ativação e diferenciação de células B. No sistema hematopoético, a expressão do gene Pax-5 inicia nas fases precoces de diferenciação da célula $\mathrm{B}$ e é importante para o desenvolvimento e progressão destas células. ${ }^{17,19,20}$ Dessa forma, a inativação do gene Pax-5 pode induzir um bloqueio da diferenciação de células $\mathrm{B}$, reduzindo o número de células maduras. ${ }^{24}$

A PASB tem sido observada em muitos linfomas de 
células B, mas nunca em neoplasias de células T. Esta pode ser um valioso marcador diagnóstico para neoplasias linfoides de células B em biópsias emblocadas em parafina, porque é expresso fortemente nestas amostras e é negativo em proliferações linfoblástica de células T. . $^{13,23,25}$

Estudos recentes envolvendo o fator de transcrição Pax-5 mostram que a PASB é expressa na maioria dos LNH de linhagem B, mas sofrem uma diminuição da expressão nas células clássicas do LH(CRS) ${ }^{26}$ Assim, como o LH e o LDGCB são duas neoplasias de incidência relativamente alta, e considerando as dificuldades existentes em relação ao diagnóstico diferencial, principalmente em amostras com escassa massa tumoral, neste trabalho analisamos a marcação da proteína Pax-5 em biópsias de mediastino de pacientes comLHe LDGCB.

\section{Casuística e Métodos}

Foram avaliados 14 pacientes com diagnóstico prévio de LH ou LDGCB, em amostras de mediastino, do Serviço de Anatomia Patológica do Cepon, no período de 2000 a 2006. O diagnóstico laboratorial foi realizado por imuno-histoquímica de acordo com o painel de anticorpos demonstrado na Tabela 1. Após parecer favorável do Comitê de Ética em Pesquisa com Seres Humanos do Cepon (parecer $n^{\circ}$ 018/ 2006), as amostras dos pacientes com diagnóstico de LH e LDGCB foram submetidas à reação de imuno-histoquímica para avaliação da expressão da proteína PAX-5. Os blocos de parafina, com amostra dos pacientes processada histologicamente, foram cortados em micrótomo rotativo, obtendo- se cortes de 2 a $3 \mu \mathrm{m}$ de espessura, montados sobre lâminas silanadas (Leica, São Paulo, Brasil). Após fixação em estufa a $50^{\circ} \mathrm{C}$ por uma hora, os cortes foram desparafinados em xilol, e hidratados por passagens sucessivas em etanol com concentrações decrescentes. Após este procedimento, bloqueou-se a peroxidase endógena, para evitar reações inespecíficas falso-positivas, com solução de peróxido de hidrogênio a $3 \%$ e metanol absoluto, em um banho de vinte minutos. Seguiu-se com lavagens em água destilada e tampão salinafosfato pH 7,2 (PBS, composição: $\mathrm{NaCl} 137$ mM, KCl 2 mM e tampão fosfato $10 \mathrm{mM}$ ) (Laborclin, Pinhais, Paraná, Brasil). Posteriormente, a amostra foi submetida à reativação antigênica em um tampão $\mathrm{pH} 6$ à base de citrato (Dako, Carpinteria, CA, USA), diluído 1:10 e mantido em banho-maria ajustado para $95^{\circ}-98^{\circ} \mathrm{C}$ durante 45 minutos. Em seguida, as lâminas foram mantidas à temperatura ambiente durante vinte minutos e lavadas com água destilada e tampão PBS. O anticorpo monoclonal anti-Pax-5 (Clone 1EW, mouse IgG1, Novocastra, NewCastle, UK) foi diluído a 1:100, em tampão Tris$\mathrm{HCl}(0,05 \mathrm{~mol} / \mathrm{L})$. Após este procedimento, a solução contendo o anticorpo foi adicionada aos cortes teciduais e as lâminas foram mantidas em câmara úmida na geladeira a $2^{\circ}-8^{\circ}$ $\mathrm{C}$, over night. Na sequência, as lâminas foram lavadas com tampão PBS duas vezes, por cinco minutos cada, à temperatura ambiente, e foram incubadas com anticorpo secundário biotinilado anti-IgG/IgM (Dako Corporation, Carpinteria, USA) por trinta minutos. Logo após esta etapa, as lâminas foram novamente lavadas com PBS e incubadas com estreptavidina conjugada à peroxidase (Dako Corporation, Carpinteria, USA) por mais trinta minutos. Posteriormente às

Tabela 1. Perfil imuno-histoquímico dos casos selecionados

\begin{tabular}{|c|c|c|c|c|c|c|c|c|c|c|c|}
\hline \multirow[t]{2}{*}{ Pacientes } & \multicolumn{10}{|c|}{ Anticorpos } & \multirow[t]{2}{*}{ Diagnóstico } \\
\hline & LCA & CD3 & CD5 & CD10 & $\mathrm{CD} 20$ & CD30 & CD45RO & CD15 & KI67 & FASCINA & \\
\hline Caso 1 & $P$ & $\mathrm{~N}$ & & & $\mathrm{P}$ & $\mathrm{N}$ & & $\mathrm{N}$ & & & LDGCB \\
\hline Caso 2 & $P$ & $\mathrm{~N}$ & & & $P$ & & $\mathrm{~N}$ & & $60 \%$ & & LDGCB \\
\hline Caso 3 & $P$ & & $\mathrm{~N}$ & & $P$ & $\mathrm{~N}$ & & $\mathrm{~N}$ & $60 \%$ & & LDGCB \\
\hline Caso 4 & $P$ & & & & $P$ & $\mathrm{~N}$ & $\mathrm{~N}$ & $\mathrm{~N}$ & $80 \%$ & $\mathrm{~N}$ & LDGCB \\
\hline Caso 5 & 1 & & & & $P$ & $P$ & & 1 & & $P$ & LDGCB \\
\hline Caso 6 & $P$ & $\mathrm{~N}$ & & & $P$ & $P$ & & $\mathrm{~N}$ & $50 \%$ & & LDGCB \\
\hline Caso 7 & $\mathrm{~N}$ & & & & $\mathrm{~N}$ & $P$ & & $P$ & & $P$ & $\mathrm{LH}$ \\
\hline Caso 8 & $P$ & $\mathrm{~N}$ & & $\mathrm{~N}$ & P & $P$ & & 1 & $60 \%$ & & LDGCB \\
\hline Caso 9 & $P$ & & $\mathrm{~N}$ & $P$ & $\mathrm{P}$ & $\mathrm{N}$ & & 1 & & $\mathrm{~N}$ & LDGCB \\
\hline Caso 10 & $\mathrm{~N}$ & & & & $\mathrm{~N}$ & $P$ & & $\mathrm{P}$ & & $P$ & $\mathrm{LH}$ \\
\hline Caso 11 & $P$ & $P$ & & & $\mathrm{P}$ & $P$ & & 1 & & $P$ & LDGCB \\
\hline Caso 12 & $P$ & $P$ & & & $P$ & 1 & & 1 & & 1 & LH \\
\hline Caso 13 & $P$ & & $\mathrm{~N}$ & $\mathrm{~N}$ & $P$ & $\mathrm{~N}$ & & $\mathrm{~N}$ & $20 \%$ & & LDGCB \\
\hline Caso 14 & $\mathrm{~N}$ & $\mathrm{~N}$ & $\mathrm{~N}$ & & $\mathrm{~N}$ & $P$ & $\mathrm{~N}$ & $\mathrm{P}$ & & $P$ & LH \\
\hline
\end{tabular}

$\mathrm{P}=$ positivo; $\mathrm{N}=$ negativo; $\mathrm{I}$ = inconclusivo. 
lavagens já mencionadas, as amostras foram submetidas a revelação colorimétrica com uma solução cromógena, contendo $0,03 \%$ de 3,3'-diaminobenzidina, previamente diluída em tampão imidazol pH 7,2 e peróxido de hidrogênio a 0,3\% (Dako Cytomation, Carpinteria, CA, USA). Após a revelação, foram realizadas as contracolorações das lâminas com solução de hematoxilina de Harris, desidratação através de passagem das lâminas em concentrações crescentes de etanol, diafanização em xilol e montagem em Entellan ${ }^{\circledR}$ (Merck, São Paulo, Brasil). A leitura das lâminas foi realizada em microscópio óptico comum (Leica, São Paulo, Brasil), em aumento de 200X e 400X, onde todos os campos da lâmina foram analisados. O resultado positivo foi revelado pelo aparecimento de coloração castanha no local da marcação pelo anticorpo (núcleo celular). A intensidade da marcação do anticorpo PAX-5 foi graduada da seguinte forma:

$$
\begin{aligned}
& \text {-: negativo } \\
& + \text { : fracamente positivo } \\
& \text { ++: moderadamente positivo } \\
& \text { +++: fortemente positivo }
\end{aligned}
$$

A análise estatística foi realizada utilizando-se o programa GraphPad Instal ${ }^{\circledR}$. A associação entre as diferentes variáveis foi analisada pelo teste do $\chi 2$, onde o $\rho<0,05$ foi considerado estatísticamente significativo.

\section{Resultados}

Inicialmente, foram selecionados 21 pacientes a partir do diagnóstico de LH ou LDGCB. Entretanto, somente foi possível a obtenção do material de biópsia do tecido tumoral adequado tecnicamente para análise, bem como do termo de consentimento livre e esclarecido de 14 pacientes. Sendo assim, a marcação nuclear da proteína Pax-5 foi determinada nestas 14 amostras. A partir do perfil imuno-histoquímico dos casos selecionados, foi realizada a revisão diagnóstica dos pacientes com linfoma de mediastino. Como pode ser observado na Tabela 1, do total de pacientes portadores de linfoma de mediastino, dez $(71,4 \%)$ apresentaram diagnóstico de LDGCB e quatro $(28,6 \%)$ de LH.

Como pode ser visto na Tabela 2, os marcadores imunofenotípicos muitas vezes não são específicos o suficiente

Tabela 2. Expressão de marcadores imuno-histoquímicos por número de casos analisados

\begin{tabular}{ccc}
\hline Anticorpos & LH $(n=4)$ & LDGCB $(n=10)$ \\
\hline CD30 & $3 / 4^{\star}$ & $4 / 9^{\star \star}$ \\
CD15 & $3 / 4^{\star}$ & $0 / 9^{\star},{ }^{\star \star}$ \\
CD20 & $1 / 4$ & $10 / 10$ \\
CD45 (LCA) & $1 / 4$ & $9 / 10^{*}$ \\
FASCINA & $3 / 4^{\star}$ & $2 / 4^{\star \star}$ \\
\hline
\end{tabular}

* presença de resultado(s) inconclusivo(s)

** anticorpo não realizado em um(ns) caso(s)
Tabela 3. Detecção da expressão de Pax-5 pela técnica de imuno-histoquimica em LH e LDGCB

\begin{tabular}{ccc}
\hline Pacientes & Anticorpo PAX-5 & Diagnóstico \\
\hline Caso 1 & +++ & LDGCB \\
Caso 2 & ++ & LDGCB \\
Caso 3 & + & LDGCB \\
Caso 4 & ++ & LDGCB \\
Caso 5 & +++ & LDGCB \\
Caso 6 & + & LDGCB \\
Caso 7 & - & LH \\
Caso 8 & ++ & LDGCB \\
Caso 9 & ++ & LDGCB \\
Caso 10 & + & LH \\
Caso 11 & +++ & LDGCB \\
Caso 12 & - & LH \\
Caso 13 & ++ & LDGCB \\
Caso 14 & + & LH \\
\hline$+++=$ fortemente positivo,,$++=$ moderadamente positivo; \\
$+=$ fracamente positivo; $-=$ negativo \\
\hline
\end{tabular}
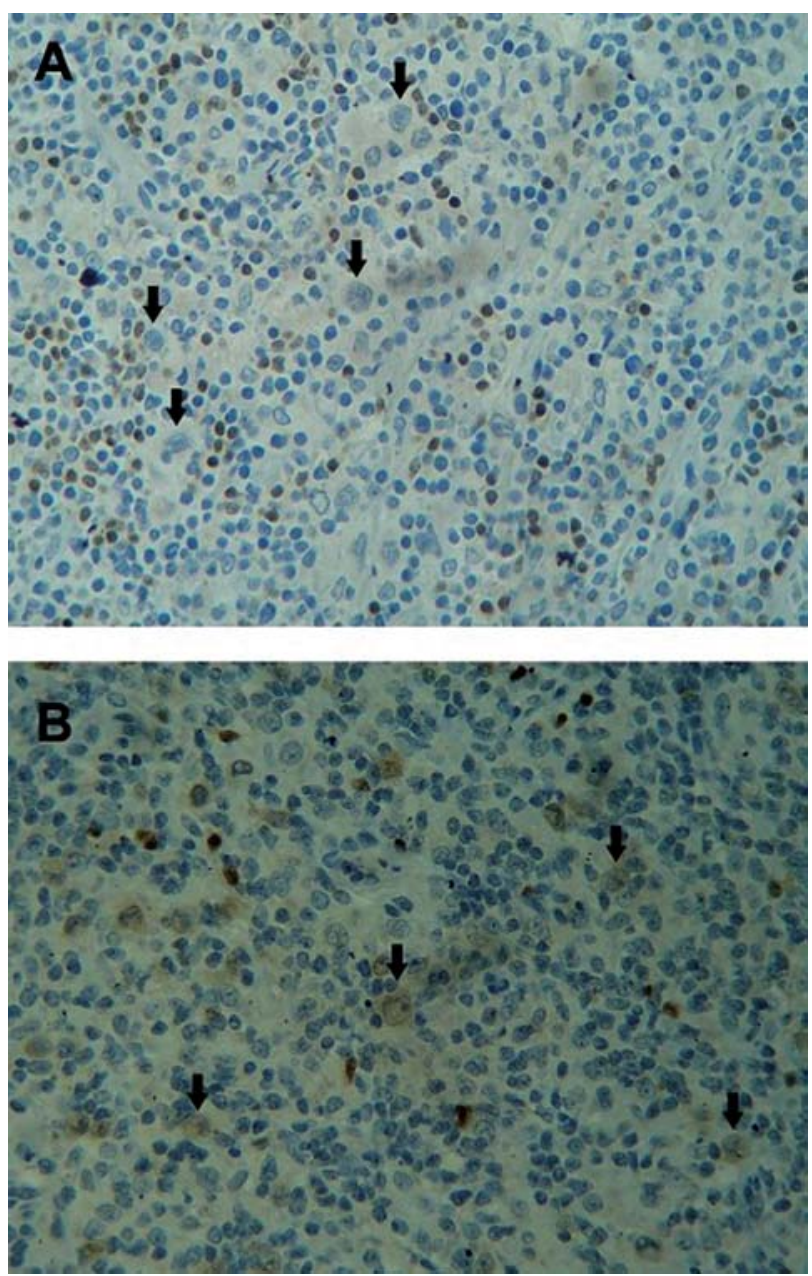

Figura 1. Marcação do anticorpo PAX-5 em biópsia de paciente com LH. Painel A: Marcação negativa das células de RS; Painel B: Marcação fracamante positiva nas células de RS (A e B, aumento de $400 \mathrm{X})$ 

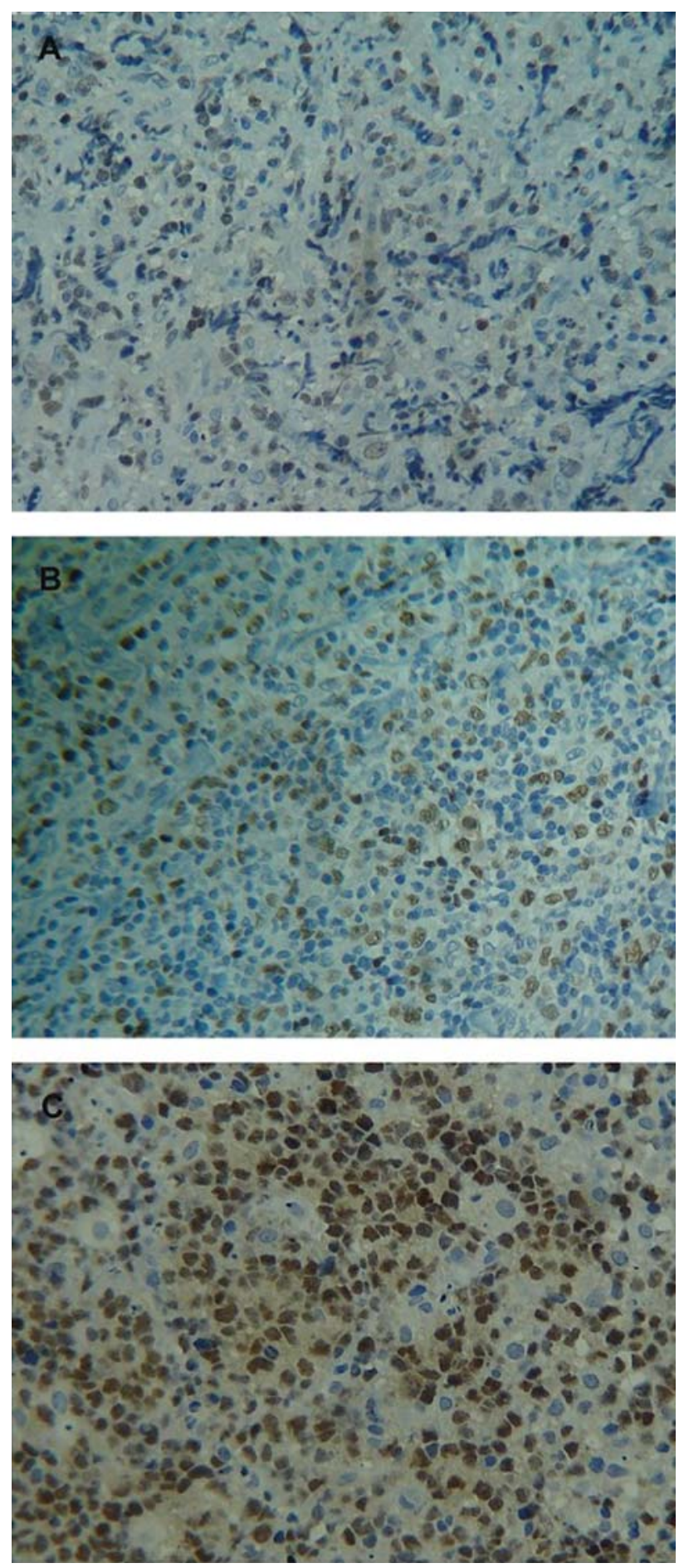

Figura 2. Marcação do anticorpo PAX-5 em biópsia de paciente com LDGCB. Painel A: Marcação fracamante positiva em LDGCB; Painel B: Marcação moderadamente positiva em LDGCB; Painel C: Marcação fortemente positiva em LDGCB (A, B e C, aumento de $400 \mathrm{X})$ para o diagnóstico diferencial entre o LH e o LDGCB. Por isso, a investigação de novos alvos de diagnóstico diferencial se faz importante. Dessa forma, analisamos a expressão diferencial da proteína Pax-5 nas 14 amostras de biópsias de pacientes com LH ou LDGCB. A Tabela 3 mostra que, nos casos de LDGCB, a marcação da proteína Pax-5, variou de fracamente positiva (20\%) a fortemente positiva (30\%), e $50 \%$ foi moderadamente positiva. Entretanto, nos casos de LH, dois casos foram fracamente positivos e os outros dois negativos. Nas Figuras 1 e 2, pode-se visualizar o padrão de marcação do anticorpo Pax-5 nos casos de LH e LDGCB, respectivamente. A diferença da marcação do anticorpo Pax-5 entre LH e LDGCB foi estatisticamente significativa $\left(\rho<0,0001, \chi^{2}\right.$ test $)$.

\section{Discussão}

Como visto anteriormente, o LH e o LDGCB são neoplasias de células $\mathrm{B}$, que podem apresentar marcadores imunofenotípicos em comum, e, por isso, o diagnóstico diferencial entre eles muitas vezes é difícil, principalmente em biópsias de mediastino.

Como pode ser visto nas Tabelas 1 e 2, o painel realizado para o diagnóstico de LH e LDGCB muitas vezes não é esclarecedor. Os anticorpos CD3, CD5 e CD45RO, marcadores de células $\mathrm{T}$, foram adicionados no painel imuno-histoquímico para excluir neoplasias derivadas de células T. Alguns anticorpos considerados úteis como ferramentas diagnósticas entre LH e LDGCB não apresentaram resultados elucidativos. Os antígenos CD30 e Fascina, presentes em células de Hodgkin, não evidenciaram a especificidade descrita na literatura, ${ }^{14}$ uma vez que marcaram tanto células de Hodgkin como grandes células B. Entretanto, o anticorpo CD15, que marca CRS, apresentou resultados compatíveis, uma vez que foi negativo em LDGCB e positivo em LH. Porém, este anticorpo, juntamente com o LCA e Fascina, mostrou-se duvidoso no diagnóstico de alguns casos apresentados.

Considerando os problemas apresentados com os anticorpos rotineiramente utilizados no diagnóstico diferencial de $\mathrm{LH}$ e LDGCB, a investigação de um marcador específico para esses linfomas torna-se um alvo de diagnóstico laboratorial de grande importância.

Segundo Falini e Manson, ${ }^{25}$ a detecção do Pax-5 pode ser um valioso marcador diagnóstico para neoplasias linfoides de células B, em biópsias emblocadas em parafina, pois é fortemente expresso nestas amostras, e é negativo em proliferações linfoblástica de células T. A proteína Pax-5 pode ser útil para o diagnóstico, pois, além de ser detectável em todos os estágios de maturação de células B, apresenta marcação intranuclear. Esse aspecto é importante, pois marcações membranares e/ou citoplasmáticas em biópsias de mediastino são de difícil visualização, visto que as células encontram-se muito próximas umas das outras, o que torna difícil saber qual célula está realmente marcada. Além disso, 
o ensaio de imuno-histoquímica pode apresentar reação de fundo, o que dificulta a visualização da marcação citoplasmática.

Neste trabalho, a técnica de imuno-histoquímica mostrou-se eficiente para a detecção da proteína Pax-5 (Tabela 3), em amostras de biópsias de LH e LDGCB. Evidenciou-se esta proteína através de marcação exclusivamente nuclear, sendo mais fidedigna devido à disposição celular.

Krenacs et $a l^{27}$ evidenciaram intensidades variadas de marcação do Pax-5 em casos de LDGCB e em LH, e concluíram que a alta expressão de Pax-5, particularmente naqueles encontrados em LDGCB, pode ser devido à expressão desregulada de PASB/Pax-5, o que confirma o possível papel do Pax-5 em patologias malignas envolvendo linfócitos B. Em 2002, Torlakovic et a $l^{19}$ descreveram o uso do anticorpo Pax-5 para identificação e confirmação de linfomas de células B, em biópsias emblocadas em parafina e fixadas em formol. Esse mesmo estudo caracterizou a marcação exclusivamente nuclear do Pax-5 com 100\% de positividade forte em LDGCB, e $92 \%$ de positividade fraca para LH. Nossos resultados corroboram com essas afirmativas, pois $100 \%$ dos casos de LDGCB apresentaram positividade nuclear. Destes, 30\% mostraram positividade forte $(+++) ; 50 \%$, moderada $(++) ; 20 \%$ fraca (+). Portanto, estes resultados mostram que o Pax-5 é um bom marcador para LDGCB, pois se apresentou positivo em todos os casos analisados, inclusive foi decisivo naqueles casos em que os anticorpos LCA, CD15 e Fascina, considerados de grande importância diagnóstica, tiveram marcação duvidosa. Em relação ao LH, embora a amostragem tenha sido pequena, a marcação com o Pax-5 mostrou uma tendência de fracamente positiva a negativa, diferenciando do padrão de marcação geralmente forte do LDGCB.

Foi observado que a intensidade de marcação da proteína Pax-5 variou não apenas entre os dois subtipos de linfoma analisados, mas também entre os casos de mesmo diagnóstico, e que este fato pode estar relacionado ao grau de malignidade. ${ }^{27} \mathrm{~A}$ marcação focal e fraca, ou até negativa, do Pax-5 em LH, pode ser um ponto importante para o diagnóstico diferencial, uma vez que difere muito da marcação visualizada no LDGCB. Assim, é possível concluir que o anticorpo Pax-5 é um bom marcador para ser usado em conjunto com outros marcadores no painel de rotina e, quando associado à clínica, pode ser muito útil no diagnóstico.

\section{Abstract}

Hodgkin's Lymphoma (HL) and diffuse large B-cell Lymphoma (DLBCL) are neoplasias derived from $B$ cells that present the same immunophenotypic markers, making the differential diagnosis between them very difficult particularly in cases where morphological overlapping occurs. An extra difficulty exists when the tumor is located in the mediastinum, thereby demanding a more invasive biopsy. In addition, frequently an excessively small sample is collected, putting the analysis of the morphological characteristics of lymphoproliferation at risk. The goal of this study was to evaluate $P A X-5$ as a marker to distinguish HL from DLBCL. Overall, 10 out of 14 studied cases had a diagnosis of DLBCL and 4 patients of $H L$. The Pax-5 immunohistochemical staining showed 100\% positivity in the LBCL study group. However, $30 \%$ showed strong positivity $(+++), 50 \%$ moderate $(++)$ and $20 \%$ weak $(+)$. On the other hand, $50 \%$ of the HL group showed a weak focal pattern of staining of the Reed/Sternberg Cells (RSC), whereas the other 50\% showed negativity. The weak focal pattern as well as the negative staining pattern of PAX-5 in HL may be an important key in the differential diagnosis as it is very different from DLBCL. Hence, we suggest that the PAX-5 antibody is a good immunomarker and may be used with other markers in the laboratory routine. It is also very useful when associated to clinical features of patients to reach a differential diagnosis between DLBCL and HL mediastinal lymphoma. Rev. Bras. Hematol. Hemoter.

Key words: Hodgkin's lymphoma; diffuse large B-cell lymphoma; PAX-5 antibody; immunohistochemistry.

\section{Referências Bibliográficas}

1. Hoffbrand AV, Pettit JE, Moss PAH. Fundamento em Hematologia. Artmed Bookman; 2004. p. 358.

2. Soares FA. A Classificação Morfológica e os Aspectos Histológicos do Linfoma de Hodgkin. In: Zago MA, Falcão RP, Pasquini R. Hematologia. Fundamentos e Prática. Edição revisada e ampliada. São Paulo: Atheneu; 2004. p. 599-607.

3. Schwering, I, Bräuninger A, Klein U et al. Loss of the B-lineagespecific gene expression program in Hodgkin and Reed-Sternberg cells of Hodgkin lymphoma. Blood 2003;101(4):1505-12.

4. Jaffe ES, Harris NL, Stein $\mathrm{H}$ et al. World Health Organization Classification of Tumours. Tumours of Haematopoeitic and Lymphoid Tissues. 3nd ed. Lyon: IARC Press; 2001. 351p.

5. American Cancer Society - National Comprehensive Cancer Network. Non-Hodgking's lymphoma: Treatment guideline's for pacients. 2004. p. 80.

6. Swerdlow SH, Campo E, Harris NL, Jaffe ES, Pileri SA, Stein H, et al. WHO Classification of Tumours of Haematopoietic and Lymphoid Tissues. 4nd ed. Lyon: IARC Press, 2008. 439 p.

7. Chan JKC. The new World Health Organization classification of lymphoms: the past, the present and the future. Hematological Oncol 2001;19:129-150.

8. Dunphy $\mathrm{CH}$, Craver JL, Emerson WA. Demonstration of composite nodal B-cell lymphoma and subsequent Hodgkin's disease by flow cytometry and immunohistochemistry - case report and review of the literature. Arch Pathol Lab Med. 1997;121(6):637-40.

9. Kirchner EM, Ebsen M, Kirchner J et al. Transformation of Hodgkin's disease to high-grade B-cell lymphoma: remission after rituximab monotherapy. Ann Oncol. 2001;12(8):1169-71.

10. Fleming MD, Shahsafaei MS, Dorfman DM. Absence of dendritic reticulum cells staining is helpful for distinguishing T-cell rich Bcell lymphoma from lymphocyte predominance Hodgkin 1s disease. Appl Immunohistochem 1998;6:16-22.

11. Rüdiger T, Ott G, Ott MM, Müller-Deubert SM, MüllerHermelink HK. Differential diagnosis between classic Hodgkin's lymphoma, T-cell-rich B-cell lymphoma, and paragranuloma by paraffin immunohistochemistry. Am J Surg Pathol. 1998; 22(10):1184-91. 
12. Browne P, Petrosyan K, Hernandes A et al. The B-cell transcription factors BSAP, Oct-2, and BOB.1 and the pan-B-cell markers CD20, $\mathrm{CD} 22$, and CD79a are useful in the differential diagnosis of classic Hodgkin lymphoma. Am J Clin Pathol. 2003;120(5):767-77.

13. Dong HY, Browne P, Liu Z, Gangi M. PAX-5 is invariably expressed in B-cell lymphomas without plasma cell differentiation. Histopathology 2008;53(3):278-87.

14. Dabbs DJ. (Ed). Diagnostic Immunohistochemistry. $2^{\text {nd }}$ ed. Philadelphia: Elsevier Inc., 2006. 828 p.

15. Mason DY, Cordell JL, Brown MH, et al. CD79a: a novel marker for B-cell neoplasms in routinely processed tissue samples. Blood 1995;86(4):1453-9.

16. Robichaud GA, Nardini M, Laflamme M et al. Human Pax-5 Cterminal isoforms possess distinct transactivation properties and are differenttialy modulated in normal and malignant B cells. J Biol Chem. 2004;279(48):49956-63.

17. Nutt SL, Thevenin C, Busslinger M. Essential functions of Pax-5 (BSAP) in pro-B cell development. Immunobiology 1997;198(13):227-35.

18. Hagman J, Wheat W, Fitzsimmons D, et al. Pax-5/BSAP: regulator of specific gene expression and differentiation in B lymphocytes. Curr Top Microbiol Immunol 2000;245(1):169-94.

19. Torlakovic E, Torlakivic G, Nguyen PL, et al. The value of antipax-5 immunostaining in routinely fixed and paraffin-embedded sections: a novel pan pre-B and B-cell marker. Am J Surg Pathol. 2002;26(10):1343-50.

20. Mhawech-Fauceglia P, Saxena R, Zhang S, Terracciano L, Sauter G, Chadhuri A, et al. Pax-5 immunoexpression in various types of benign and malignant tumours: a high-throughput tissue microarray analysis. J Clin Pathol 2007;60(6):709-714.

21. Adams B, Dörfler P, Aguzzi A, et al. Pax-5 encodes the transcription factor BSAP and is expressed in B lymphocytes, the developing CNS, and adult testis. Genes Dev 1992;6(9):589-607.

22. Fitzsimmons D, Lutz R, Wheat W, et al. Highly conserved amino acids in Pax and Ets proteins are required for DNA binding and ternary complex assembly. Nucleic Acids Res 2001;29(20):4154-65.
23. Dong HY, Liu W, Cohen P, et al. B-cell specific activation protein encoded by the PAX-5 gene is commonly expressed in merkel cell carcinoma and small cell carcinomas. Am J Surg Pathol 2005; 29(5):687-92.

24. Wakatsuki Y, Neurath MF, Max EE, et al. The B cell-specific transcription factor BSAP regulates B cell proliferation. J Exp Med 1994;179(4):1099-1108.

25. Falini B, Manson DY. Proteins encoded by genes involved in chromosomal alterations in lymphoma and leukemia: clinical value of their detection by immunocytochemistry. Blood 2002;99 (2):409-426.

26. McCune RC, Syrbu SI, Vasef MA. Expression profiling of transcription factors Pax-5, Oct-1, Oct-2, BOB.1, and PU.1 in Hodgkin's and non-Hodgkin's lymphomas: a comparative study using high throughput tissue microarrays. Mod Pathol. 2006; 19(7):1010-8.

27. Krenacs L, Himmelmann AW, Quintanilla-Martinez L et al. Transcription factor B-cell-specific activator protein (BSAP) is differentially expressed in B cells and in subsets of B-cell lymphomas. Blood 1998;92(4):1308-16.

Avaliação: Editor e dois revisores externos

Conflito de interesse: sem conflito de interesse

Recebido: 17/12/2008

Aceito após modificações: 02/07/2009 